\title{
EDITORIAL
}

\section{Special issue on representative articles from 2011 Denver X-ray Conference}

In early 2003, Powder Diffraction and the Denver X-ray Conference agreed to a collaboration to publish representative Denver X-ray Conference articles in the special June issue of Powder Diffraction. For the past 10 years, the annual publication of the special June issue has increased the service and the number of technical articles to the readers of Powder Diffraction, as well as the circulation of the representative Denver X-ray Conference articles for their authors.

$\mathrm{X}$-ray fluorescence and X-ray diffraction articles published in the issue were recommended, reviewed and edited by Editors-in-Chief (namely, Dr Thomas Blanton and Dr George
Havrilla) and members of the Denver X-ray Conference Organising Committee. I hope that our readers will find the articles appeared in this issue interesting and useful.

I also want to thank Nicole Ernst Boris, Denise Flaherty and Carly Bray of International Centre for Diffraction Data as well as the staff of Cambridge University Press for making sure that everything is in order for the June publication.

Ting C. Huang IBM Almaden, Physical Sciences. Email: tinghuang@tinghuang.com 